\title{
Two millennia of climate variability in the Central Mediterranean
}

\author{
C. Taricco $^{1}$, M. Ghil ${ }^{2,3}$, S. Alessio ${ }^{1}$, and G. Vivaldo ${ }^{1}$ \\ ${ }^{1}$ Dipartimento di Fisica Generale dell'Università, and Istituto di Fisica dello Spazio Interplanetario-INAF, Torino, Italy \\ ${ }^{2}$ Geosciences Department \& Laboratoire de Météorologie Dynamique (CNRS and IPSL), Ecole Normale Supérieure, \\ Paris, France \\ ${ }^{3}$ Department of Atmospheric and Oceanic Sciences \& Institute of Geophysics and Planetary Physics, University of California, \\ Los Angeles, CA, USA
}

Received: 14 July 2008 - Published in Clim. Past Discuss.: 1 October 2008

Revised: 20 April 2009 - Accepted: 20 April 2009 - Published: 4 May 2009

\begin{abstract}
This experimental work addresses the need for high-resolution, long and homogeneous climatic time series that facilitate the study of climate variability over time scales of decades to millennia. We present a high-resolution record of foraminiferal $\delta^{18} \mathrm{O}$ from a Central-Mediterranean sediment core that covers the last two millennia. The record was analyzed using advanced spectral methods and shows highly significant oscillatory components with periods of roughly 600, 350, 200, 125 and 11 years. Over the last millennium, our data show several features related to known climatic periods, such as the Medieval Optimum, the Little Ice Age and a recent steep variation since the beginning of the Industrial Era. During the preceding millennium, the $\delta^{18} \mathrm{O}$ series also reveals a surprising maximum at about $0 \mathrm{AD}$, suggesting low temperatures at that time. This feature contradicts widely held ideas about the Roman Classical Period; it is, therefore, discussed at some length, by reviewing the somewhat contradictory evidence about this period.

We compare the $\delta^{18} \mathrm{O}$ record with an alkenone-derived sea surface temperature time series, obtained from cores extracted in the same Central-Mediterranean area (Gallipoli Terrace, Ionian Sea), as well as with Italian and other European temperature reconstructions over the last centuries. Based on this comparison, we show that the long-term trend and the 200-y oscillation in the records are temperature driven and have a dominant role in describing temperature variations over the last two millennia.
\end{abstract}

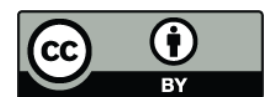

Correspondence to: C. Taricco

(taricco@ph.unito.it)

\section{Introduction}

Knowledge of long-term natural variability is required to assess anthropogenic effects on climate (Martinson et al., 1995; National Research Council of the National Academies, 2006). Instrumental temperature series, however, only cover two-three centuries (Ghil and Vautard, 1991; Martinson et al., 1995; Plaut et al., 1995; Jones et al., 1999; Folland and Karl, 2001; National Research Council of the National Academies, 2006). Therefore, in order to estimate climatic variations over the last millennium, several temperature series have been constructed, using a single type of proxy, such as tree rings (Luckman et al., 1997; Esper et al., 2002), or using multi-proxy records (Jones et al., 1998; Mann et al., 1999; Crowley, 2000). Multi-proxy records extend the spatial coverage of climate reconstructions, typically using ice cores (Jones, 1996) for high latitudes, tree rings (Luckman et al., 1997; Esper et al., 2002) for mid-latitudes, and corals (Boiseau et al., 1999; Crowley, 2000) for low latitudes. Each of these proxies, however, reflects a different combination of temperature and precipitation effects and thus the interpolation and averaging over multi-proxy records (Jones et al., 1998; Mann et al., 1999; Crowley, 2000) may lead to spurious variations in the reconstructions (Jones, 1996; Esper et al., 2004; Von Storch et al., 2004).

Marine cores with very high sedimentation rates allow one to investigate climate variations on scales of decades to millennia. They may also reflect broader features of climate, since the circulation of the basin in which they are located produces at least regional averaging (Martinson et al., 1995).

We have measured the oxygen isotope composition $\delta^{18} \mathrm{O}$ of planktonic foraminifera in a high-resolution, well-dated Central Mediterranean core. These measurements yield a homogeneous, 2200-year-long record, which captures climatic

Published by Copernicus Publications on behalf of the European Geosciences Union. 


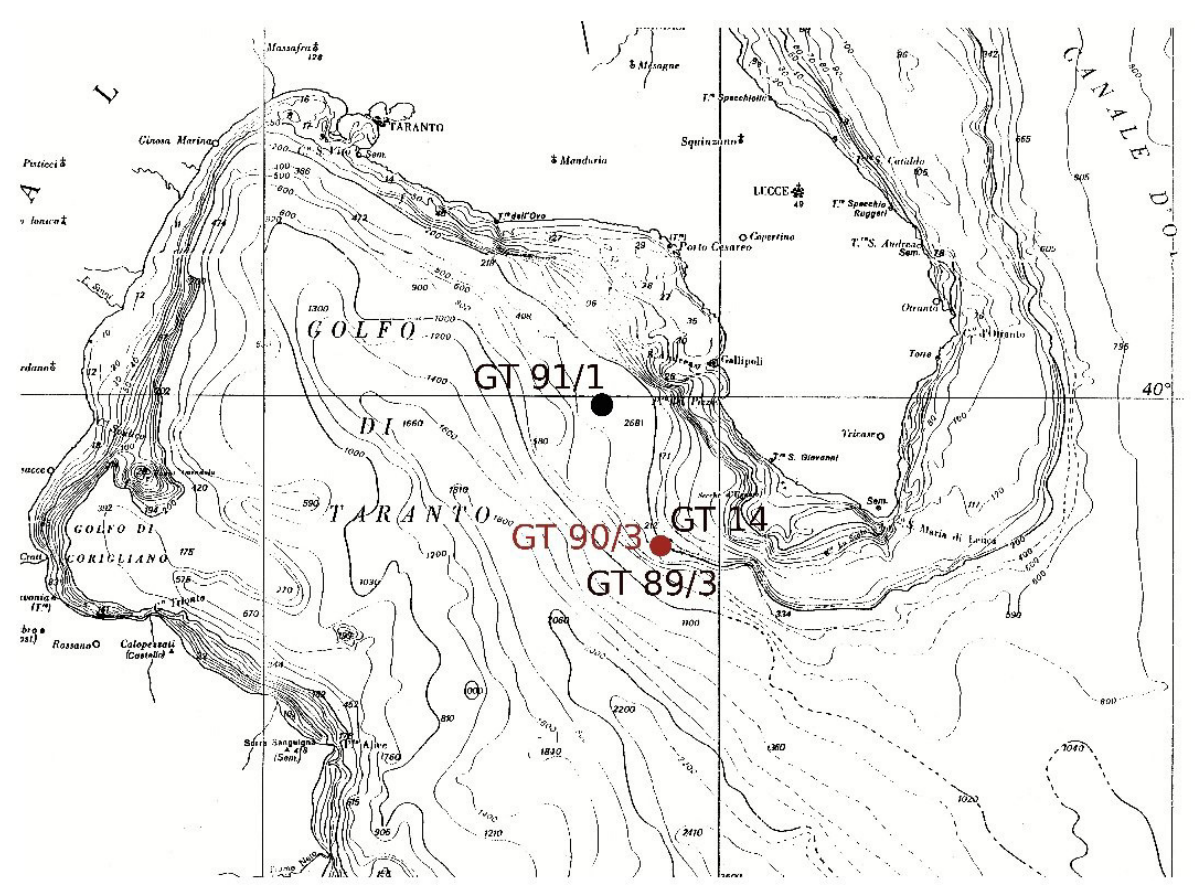

Fig. 1. Bathymetric map showing the Gallipoli Terrace in the Gulf of Taranto, Ionian Sea, from which our cores were extracted. We have measured $\delta^{18} \mathrm{O}$ in core GT90/3, drilled at $\left(39^{\circ} 45^{\prime} 53^{\prime \prime} \mathrm{N}, 17^{\circ} 53^{\prime} 33^{\prime \prime} \mathrm{E}\right)$; the core was extracted at a depth of $178 \mathrm{~m}$ and has a length of $3.57 \mathrm{~m}$. Cores GT14 and GT89/3 were drilled very close to GT90/3 and are represented by the same point on this map. The Torino cosmogeophysics group measured several profiles in the cores extracted from the Gallipoli Terrace, including ${ }^{210} \mathrm{~Pb}$ and ${ }^{137} \mathrm{Cs}$ activity, as well as pyroxene density (Cini Castagnoli et al., 1990, 1992a; Bonino et al., 1993), $\mathrm{CaCO}_{3}$ content (Cini Castagnoli et al., 1990, 1992a,b), thermoluminescence (Cini Castagnoli et al., 1997, 1998, 1999), and stable isotopes (Cini Castagnoli et al., 1999, 2002b, 2005).

oscillations with a broad range of periods, from decades to centuries. We compare our series with instrumental and alkenone-based temperature records, to gain further information about long-term climate variations.

The outline of the paper is as follows: in Sect. 2 we describe the experimental procedure for the extraction of the $\delta^{18} \mathrm{O}$ record. In Sect. 3 we present the time series so obtained and its spectral analysis, using several advanced methods for the latter. We carry out the comparison between the $\delta^{18} \mathrm{O}$ record and the other types of information on European and Mediterranean temperatures in Sect. 4. In Sect. 5, we review the contradictory information on the Roman Classical Period. Concluding remarks follow in Sect. 6, and two appendices provide additional details on the isotopic analysis and the spectral methods, respectively.

\section{Experimental procedure}

Over the last 20 years, the Torino cosmogeophysics group has carried out the absolute dating of shallow-water Ionian Sea cores, drilled from the Gallipoli Terrace in the Gulf of Taranto (Fig. 1). This carbonatic mud deposit is located at about $200 \mathrm{~m}$ of water depth. The high accuracy of the dating is made possible by the closeness of the drilling site to the volcanic Campanian area, a region that is unique in the world by its detailed historical documentation of volcanic eruptions over the last two millennia.

The markers of these eruptions were identified along the cores as peaks of the number density of clinopyroxene crystals, carried by the prevailing westerly winds from their source into the Ionian Sea and deposited there as part of marine sediments. The time-depth relation for the cores retrieved from the Gallipoli Terrace (Bonino et al., 1993; Cini Castagnoli et al., 1990, 1992a, 1999, 2002a; Vivaldo et al., 2009) was obtained by tephroanalysis; this analysis confirmed, improved and extended to the deeper part of the core the dating obtained in the upper $20 \mathrm{~cm}$ by the ${ }^{210} \mathrm{~Pb}$ method (Krishnaswamy et al., 1971; Bonino et al., 1993). Taricco et al. (2008) recently confirmed this dating by applying advanced statistical procedures (Guo et al., 1999; Naveau et al., 2003).

The cores were sampled every $2.5 \mathrm{~mm}$ and the number density of clinopyroxenes of clear volcanic origin, characterized by skeletal morphology and sector zoning, was determined for the portion of the cores that covers the last two millennia. We found 22 sharp pyroxene peaks, corresponding to historical eruptions of the Campanian area, starting with the 79 AD eruption of the Vesuvius that buried Pompei and ending with its last eruption in 1944 (Arnò et al., 1987). 


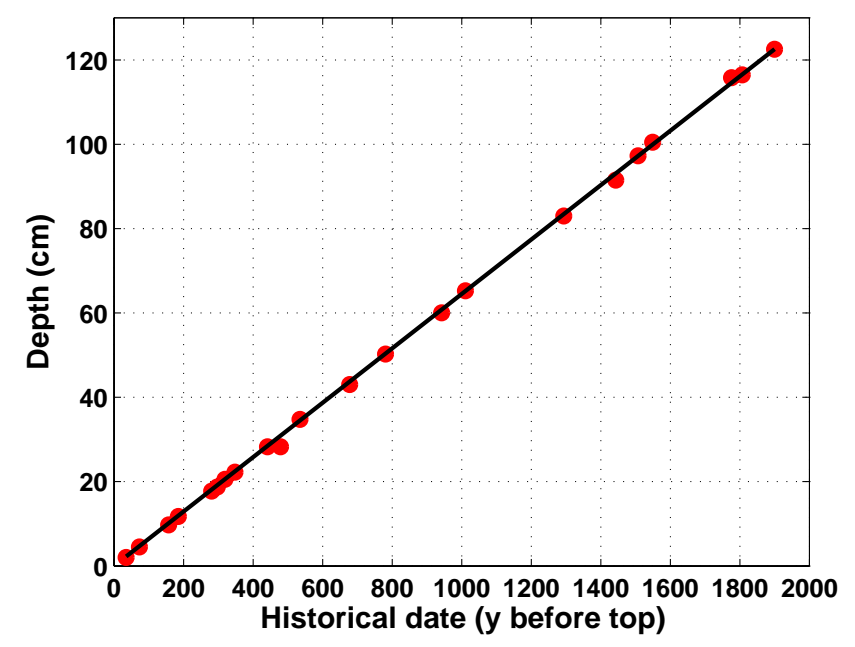

Fig. 2. Time-depth relationship. Each point in the figure represents a volcanic eruption, corresponding to a peak in the clinopyroxene time series: 22 historical volcanic eruptions occurred in the Campanian area during the last two millennia and have been identified along the core. The depth at which a volcanic peak is found in the sediment is plotted versus the historical date of the corresponding eruption, expressed in years counted backwards from 1979 AD, i.e. the date of the core top (hence, years-before-top). The straight line resulting from a linear regression fit to the experimental data is also shown. The high correlation coefficient $(r=0.99)$ attests to the goodness of the fit.

Figure 2 shows the time-depth relation over the last two millennia. Each point represents a pyroxene peak found at a given depth, and corresponding to a historical eruption. The linear regression gives $h=(0.0645 \pm 0.0002) y_{B T}$, where $h$ is depth in $\mathrm{cm}, y_{B T}$ means year-before-top (top=1979 AD) and the correlation coefficient is $r=0.99$; the slope of this line is the sedimentation rate. This relatively high sedimentation rate allows high-resolution studies in time: the sampling interval of the core, $2.5 \mathrm{~mm}$, corresponds in fact to $3.87 \mathrm{y}$.

The highly linear time-depth relation demonstrates that the sedimentation rate has remained constant, to a very good approximation, over the last two millennia. Moreover, the measurements performed in different cores retrieved from the same area showed that this rate is also uniform across the whole Gallipoli Terrace (Cini Castagnoli et al., 1990, 1992a, $2002 \mathrm{a}, \mathrm{b})$. The very sharp pyroxene peaks indicate that bioturbation by bottom-dwelling organisms is quite limited; we thus conclude that the climatic record is not significantly affected by sediment mixing.

\section{The $\delta^{18} \mathrm{O}$ series and its spectral analysis}

In Fig. 3 we present the $\delta^{18} \mathrm{O}$ measurements performed in the shells of the surface-dwelling foraminifera Globigerinoides ruber in the $3.57 \mathrm{~m}$-long core GT90/3 $\left(39^{\circ} 45^{\prime} 53^{\prime \prime} \mathrm{N}\right.$,

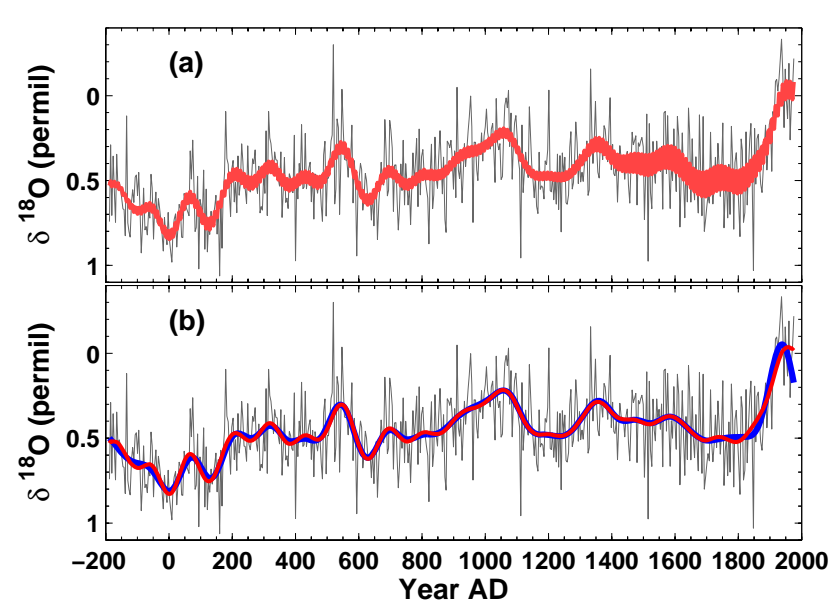

Fig. 3. Time series of the oxygen isotope ratio $\delta^{18} \mathrm{O}$ measured in the GT90/3 core; isotopic ratios plotted "upside down", to agree in tendency with temperatures. Raw data are shown in gray solid in both panels; the sampling interval is $\Delta t=3.87 \mathrm{y}$, the mean value of the raw data is $x_{m}=0.46^{0} / 00$, and their standard deviation is $\sigma_{x}=0.23^{0} / 00$. (a) Signal reconstruction by singular-spectrum analysis (SSA), using RCs 1-12 in red solid (see text for details); (b) signal reconstruction by Inverse-CWT (blue line, including all frequencies $f<1 / 100 \mathrm{y}^{-1}$; see text for details) and SSA long-term reconstruction (RCs $1-10$, red line).

$\left.17^{\circ} 53^{\prime} 33^{\prime \prime} \mathrm{E}\right)$. Appendix A provides details on the stableisotope analysis, completed so far for the upper $140 \mathrm{~cm}$ of this core.

The $\delta^{18} \mathrm{O}$ profile consists of a continuous record of 560 points from $200 \mathrm{BC}$ to $1979 \mathrm{AD}$, with a sampling interval of $\Delta t=3.87 \mathrm{y}$. Several features clearly correspond to distinct climatic periods: the low $\delta^{18} \mathrm{O}$ values near $1000 \mathrm{AD}$ are associated with the Medieval Optimum (MO), while the modern steep decrease since $1800 \mathrm{AD}$ leads to even lower values; relatively high values correspond to the Little Ice Age (LIA, 1600-1800 AD) and we also find high values at the beginning of the Christian Era. The latter are somewhat controversial (see Sect. 5) and we recall that the $\delta^{18} \mathrm{O}$ of foraminiferal calcite reflects changes not only in sea surface temperatures (SSTs) but also in sea-water isotopic composition. It seems advisable, therefore, to single out independent components of variability and try to identify the ones that are temperaturedriven, through comparison with local temperature records.

With this goal in mind, we analyzed the $\delta^{18} \mathrm{O}$ record by several spectral methods, including classical Fourier analysis, the maximum-entropy method (MEM) and singularspectrum analysis (SSA), as well as a number of wavelet methods, including the continuous wavelet tranform (CWT) and the maximum-overlap discrete wavelet transform (MODWT). The typical problem of classical spectral estimates, besides power leakage and high variance, is the use of a fixed basis of harmonic functions (sines and cosines). In contrast, SSA uses data-adaptive basis functions; this feature 


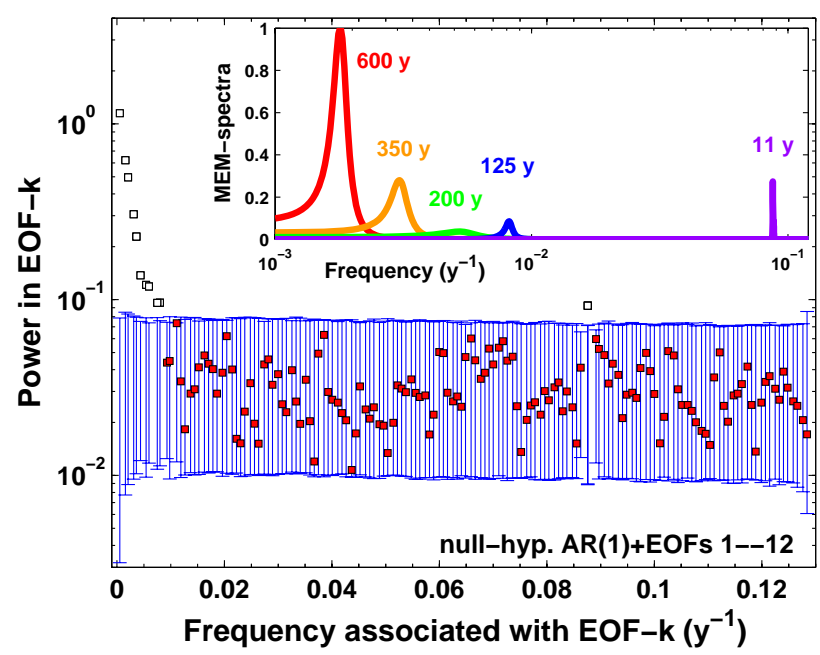

Fig. 4. Spectral properties of the $\delta^{18} \mathrm{O}$ time series shown in Fig. 3. The main panel shows the Monte-Carlo SSA test using the EOFs 112+AR(1) null-hypothesis (Allen and Smith, 1996), with 99\% error bars. The squares indicate the eigenvalues of the $\delta^{18} \mathrm{O}$ record's lagcorrelation matrix; the empty ones represent the eigenvalues that correspond to the EOFs included in the null hypothesis. Inset: individual spectra of the RCs, obtained by the maximum-entropy method (MEM; see http://www.atmos.ucla.edu/tcd/ssa).

makes the method particularly useful for climatic time series (Vautard et al., 1992), which are most often short and noisy. The SSA methodology (see Appendix B1) has in fact been applied to many instrumental and proxy climate records (e.g., Ghil and Vautard, 1991; Plaut et al., 1995; Cini Castagnoli et al., 2002a); two review papers (Ghil and Taricco, 1997; Ghil et al., 2002) and references therein cover the methodology, as well as numerous other applications.

Wavelet methods, on the other hand, are evolutionary spectral tools, characterized by good frequency resolution at low frequencies; they are particularly useful, therefore, to efficiently reveal multicentennial and millennial variations in our data. We focus here on the results obtained by SSA, using the SSA-MTM Toolkit (see Ghil et al., 2002, and the freeware toolkit at http://www.atmos.ucla.edu/tcd/ssa/), and by CWT; see the review of Torrence and Compo (1998).

SSA analysis. We adopted a window width of $M=150$ points, corresponding to a time window of $M \Delta t \simeq 580 \mathrm{y}$, in order to be able to detect oscillations with periods as long as $500-600 \mathrm{y}$, while maintaining sufficient statistical significance. We obtained coherent results for a fairly wide range of $M$ values, from 120 to 200 points.

The empirical orthogonal functions (EOFs) 1-12 account for roughly $42 \%$ of the total variance in the $\delta^{18} \mathrm{O}$ time series. Monte Carlo-SSA (Allen and Smith, 1996; see also Appendix B2) allows us to verify that the statistically significant part of the $\delta^{18} \mathrm{O}$ time series is given by the sum of these 12 components, with a residue of red noise; RCs 18 and 11-12 are significant at the $99 \%$ confidence level and RCs 9-10 at the $98 \%$ level.

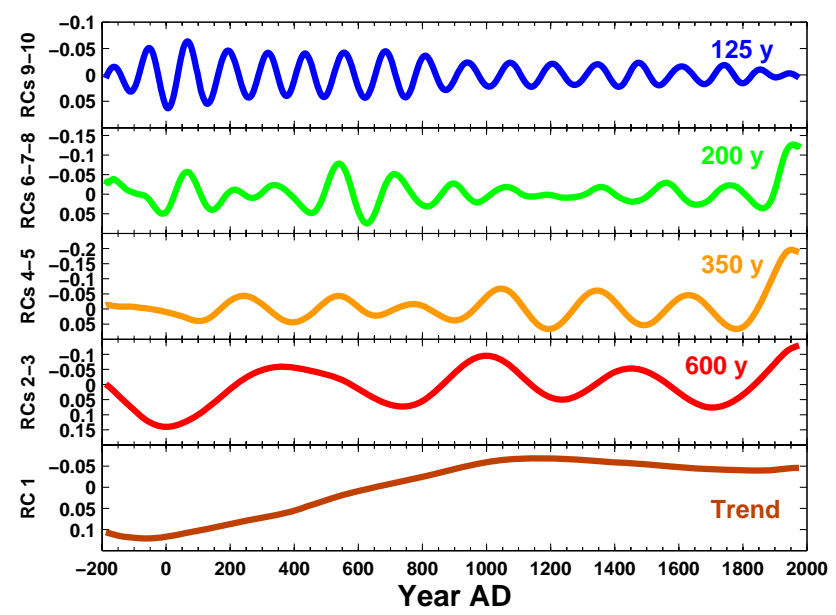

Fig. 5. Dominant SSA components of the $\delta^{18} \mathrm{O}$ record: RC 1 (trend, brown), RCs 2-3 ( $600 \mathrm{y}$, red), RCs $4-5$ ( $\sim 400 \mathrm{y}$, orange), RCs 6-8 ( $\sim 200 \mathrm{y}$, green) and RCs 9-10 (125 y, blue).

Figure 4 shows the spectral properties of our proxy record. The error bars plotted in the main panel of Fig. 4 bracket $99 \%$ of the eigenvalues obtained by the SSA of 10000 surrogate series; these series are generated by a model that superposes EOFs 1-12 onto a red-noise process, i.e. an auto-regressive process of order 1, or AR(1). The eigenvalues that lie outside the $99 \%$ error bars are only those associated with EOFs $1-12$, which have been included in the null hypothesis; this confirms that the model AR(1)+EOFs 1-12 captures the variability of our $\delta^{18} \mathrm{O}$ time series, at the $99 \%$ confidence level. We obtained this result after rejecting, at the same confidence level, a whole range of null hypotheses, including different combinations of EOFs.

All our null hypotheses include AR(1) noise; according to Allen and Smith (1996), such a test is well suited for oscillations in geophysical series because an AR(1) process does describe the bias towards low frequencies in such series, present in our $\delta^{18} \mathrm{O}$ series as well (the test against $\mathrm{AR}(1)$ alone is not shown here). This type of null hypothesis is a suitable compromise between the excessive simplicity of white noise (e.g., Vautard et al., 1992), and higher-order AR processes, which are themselves capable of oscillatory behavior.

EOF-1 corresponds to the nonlinear, data-adaptive trend of the series, while the EOF pairs 2-3, 4-5, 9-10, 11-12 and the EOF "triplet" 6-8 (Vautard et al., 1992) capture oscillatory components; the periods associated with these components were determined by MEM applied to each component separately. The periods thus obtained (and corresponding variances) equal 595 y (14.1\%), 352 y (6.7\%), 190 y (4.8\%), $125 \mathrm{y}(2.4 \%)$ and $11.4 \mathrm{y}(2.3 \%)$; see the MEM spectrum in the inset of Fig. 4. The reconstructions (Ghil and Vautard, 1991; Ghil and Taricco, 1997; Ghil et al., 2002) of the six dominant oscillations revealed by SSA are shown in Fig. 5 
and the reconstructed $\delta^{18} \mathrm{O}$ series, given by the sum of these components (RCs 1-12), is shown in panel (a) of Fig. 3, superposed on the raw data.

CWT analysis. The CWT analysis of the $\delta^{18} \mathrm{O}$ series was performed using a complex Morlet wavelet with parameter $\omega_{0}=6$. The CWT reconstructed oscillations confirm the corresponding components revealed by SSA; in panel (b) of Fig. 3 we show the signal reconstructed by Inverse CWT, including all periodicities $1 / f$ higher than a century, $f<1 / 100 \mathrm{y}^{-1}$. The latter reconstruction appears to be in excellent agreement with the SSA long-term reconstruction, using RCs 1-10 (i.e., excluding the 11-y periodicity), except for a discrepancy near the present (during the last century).

The pronounced maximum near $0 \mathrm{AD}$, the pronounced minimum at the MO (900-1100 AD) and the increase from the MO toward LIA that we found in Fig. 3 are captured by the trend RC-1, shown in the lowermost curve of Fig. 5. The 200-y oscillation, shown in the same figure, exhibits maxima around 1500, 1700 and $1900 \mathrm{AD}$, possibly associated with the Spörer, Maunder and Modern minima of solar activity.

\section{Oxygen isotope series and temperature records}

Common oscillatory components. A temperature decrease from the MO toward the LIA is present in the majority of the Northern Hemisphere (NH) temperature reconstructions covering the last millennium; see Mann et al. (1999); Luckman et al. (1997); Jones et al. (1998); Crowley (2000); Esper et al. (2002). Moreover, SSA shows that the 200-y oscillation, appearing as RCs 6-8 in our $\delta^{18} \mathrm{O}$ record, is present at a $99 \%$ confidence level in all these reconstructions (not shown).

The 300-y oscillation appears as RCs 4-5 in our record and is the dominant component (not shown) of the Jasper treering time series (Luckman et al., 1997). This feature, also found in the 1200-y, tree-ring based NH temperature reconstruction of Esper et al. (2002), is not present in other proxy records (Esper et al., 2004).

Stuiver and Braziunas (1993) found a 500-y oscillation to dominate the spectrum of atmospheric residual $\Delta^{14} C$ over the last $12 \mathrm{ky}$, and related it to salinity changes associated with an oscillation of the oceans' thermohaline circulation (Stommel, 1961; Bryan et al., 1986; Tzipermann, 1997; Ghil, 2001). In the NH temperature reconstruction of Esper et al. (2002), a similar oscillation also dominates: it is captured by their RCs $1-2$ (with $M \Delta t=500 \mathrm{y}$ ) and it is in good agreement with RCs $2-3$ of our $\delta^{18} \mathrm{O}$ record (figure not shown). This feature is not present in other proxy temperature records either (Esper et al., 2004).

In the decadal range, thanks to the high resolution of the $\delta^{18} \mathrm{O}$ series, we capture also an 11-y component (RCs 11-12) at the $99 \%$ confidence level. Cini Castagnoli et al. (1999) showed, moreover, that the $11-\mathrm{y}$ cycle in the $\delta^{18} \mathrm{O}$ of core GT90/3 is perfectly in phase with the Schwabe solar cycle (Lean et al., 1995; Labitzke and Matthes, 2003). The

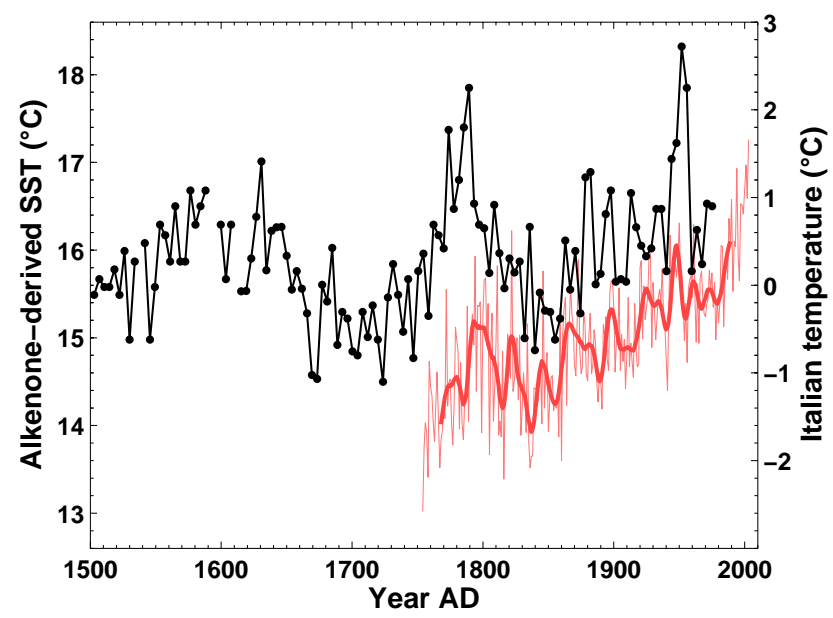

Fig. 6. Alkenone-based proxy record of sea surface temperatures (SSTs) from Versteegh et al. (2007); the record combines measurements performed on the GT89/3, GT91/1 and GT90/3 cores (solid black line), and the sampling interval is $\Delta t=3.87 \mathrm{y}$ (same as for the $\delta^{18} \mathrm{O}$ record in Fig. 3. The Italian mean-annual surface air temperatures, 1750-2003 AD (Brunetti et al., 2006) are also shown: raw data (thin red line) and low-pass filtered version (bold red line), with a cutoff at $f=1 / 10 \mathrm{y}^{-1}$. Notice that both $y$-axes $\operatorname{span} 5^{\circ} \mathrm{C}$.

presence of this cycle in global or NH temperatures (Dettinger et al., 1995; Marcus et al., 1999) is somewhat controversial, but White et al. (1997), for instance, argued that basin-average and global-average upper-ocean temperatures respond to changing solar irradiance in the 9-13-y band.

Concentrating here on the longer time scales, we may consider a millennial trend and a $200-\mathrm{y}$ oscillation as common to $\mathrm{NH}$ temperature reconstructions over the last millennium, while other oscillatory components are not. We may then hypothesize that these common components present in the $\delta^{18} \mathrm{O}$ series are temperature-driven. In order to examine this hypothesis more closely, we compared our isotopic record with local and European temperature records.

The alkenone SST record and Italian temperatures. In Fig. 6, we show the alkenone-based SST proxy record (Versteegh et al., 2007), resulting from the combination of measurements performed in three cores (GT89/3, GT91/1 and GT90/3), all extracted by our group from the Gallipoli Terrace (see Fig. 1). The measurements on core GT89/3 cover the interval 1634-1979 AD, those on GT91/1 span 1306$1708 \mathrm{AD}$, and 16 additional measurements, 1793-1851 AD, were performed on core GT90/3. In the overlapping intervals, the SST values were averaged; the time resolution is $\Delta t=3.87 \mathrm{y}$, as for the $\delta^{18} \mathrm{O}$ series.

In the same figure, we compare alkenone-derived SST values with the series of Italian annual-mean surface air temperatures from 1750 to $2003 \mathrm{AD}$ (Brunetti et al., 2006). We superimpose on the raw data in Fig. 6 a low-pass filtered version of the Italian temperature series, with a cutoff 


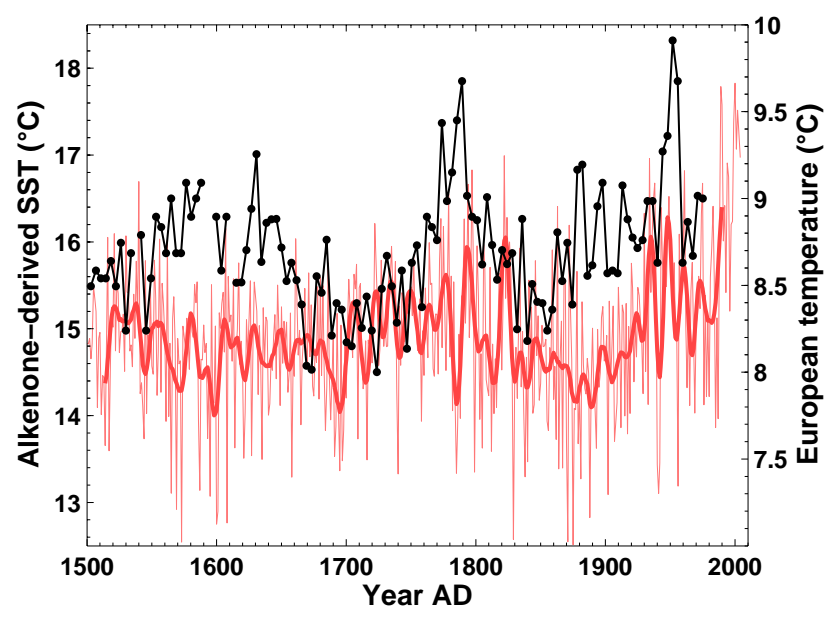

Fig. 7. Alkenone-based SST record of Fig. 6 (black line) and European mean-annual surface air temperatures, 1500-2004 AD, from Luterbacher et al. (2004); same convention as for the Italian temperature data in Fig. 6.

at $f=1 / 10 \mathrm{y}^{-1}$; this smoothing was obtained by applying an equiripple Finite Impulse Response (FIR) low-pass filter (Rabiner et al., 1975) with order 28.

Comparing SST anomalies with air temperature anomalies makes sense - as pointed out by Brohan et al. (2006) and Parker (1994). In our case, the agreement between the two profiles is surprisingly good, visually, for the long-term trend as well as for the shorter-scale variations. This agreement over the last two centuries between the alkenone-based SST measurements and the Italian temperature record provides an independent confirmation of our cores' dating.

It is worth noticing here that, in Fig. 6, the two $y$-axes both span a range of temperatures of $6^{\circ} \mathrm{C}$. From 1850 to $1979 \mathrm{AD}$ both series exhibit a remarkable increase of roughly $1.5^{\circ} \mathrm{C}$ for Italian surface air temperatures and of nearly $2^{\circ} \mathrm{C}$ for alkenone-based SSTs.

We also note a broad maximum around $1800 \mathrm{AD}$ and a narrow peak around $1950 \mathrm{AD}$ (particularly evident in the alkenone-derived SSTs), followed by a leveling off up to 1980 and by a strong increase till 2003 (not covered by the alkenone series). The modern increase of about $2^{\circ} \mathrm{C}$ indicates a local amplification with respect to the $\mathrm{NH}$ temperature increase by a factor of about 3 .

Metaxas et al. (1991) studied instrumental SSTs and surface air temperatures for the last $120 \mathrm{y}$; they found an amplification of $\mathrm{NH}$ temperature variations by a factor of $\sim 1.5$ for the Mediterranean basin as a whole and by $\sim 2$ for the Central Mediterranean. For the shallow, semi-enclosed Gulf of Taranto, we might expect an even larger amplification factor, as suggested by the alkenone data.

European air temperatures. In Fig. 7 we compare the alkenone-based SSTs with the European annual-mean temperatures reconstructed by Luterbacher et al. (2004) over the

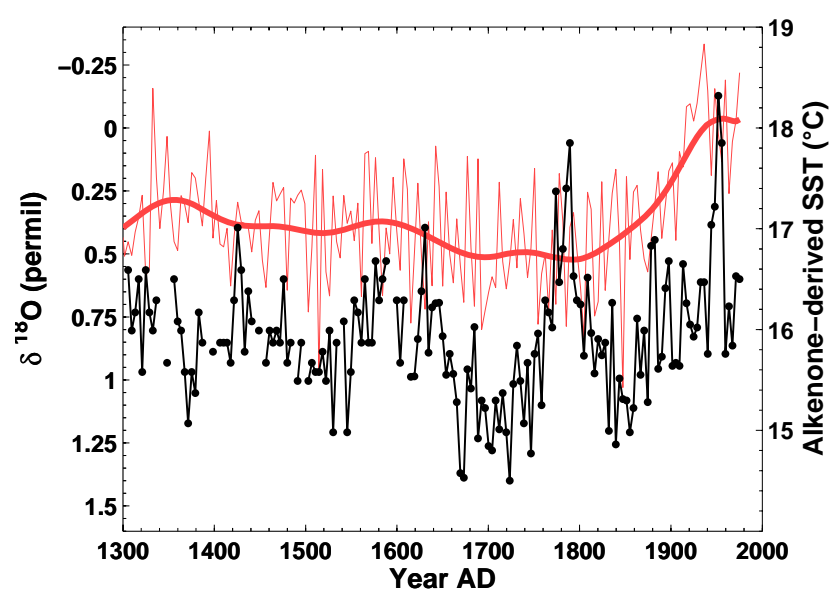

Fig. 8. Alkenone-based SST record of Fig. 6 (black line) and $\delta^{18} \mathrm{O}$ series (raw data in light solid red; SSA reconstruction by RCs 1-12 in bold solid red).

last five centuries. Superimposed on the raw surface air temperatures in Fig. 7, we show a low-pass filtered version of this record, obtained by applying the same filter used for the Italian instrumental temperature series. The agreement between this filtered series (bold red line) and the SSTs is fairly good, especially after $1700 \mathrm{AD}$, when the uncertainties of the European temperatures are smaller.

The comparison of the raw $\delta^{18} \mathrm{O}$ data and their reconstruction by RCs $1-12$ with the alkenone-derived SSTs, shown in Fig. 8, is much less satisfactory. This mismatch indicates a significant contribution of sea-water isotopic composition on the $\delta^{18} \mathrm{O}$ ratio of calcite. Over the last two centuries, however, the $\delta^{18} \mathrm{O}$ increase of about $0.5 \%$, if entirely due to temperature effects, would approximately correspond - following Shackleton and Kennet (1975) - to an increase of roughly $2^{\circ} \mathrm{C}$, a value compatible with the alkenone-derived temperature increase. This suggests that, in the modern-era variation of calcite $\delta^{18} \mathrm{O}$, the role of temperature changes is dominant, although contributions due to changes in the $\delta^{18} \mathrm{O}$ and salinity of sea water cannot be excluded, even during this period.

Visual inspection suffices to detect two striking features in the alkenone series of Fig. 8: a $\sim 200$-y oscillation, superposed on a decreasing trend that lasts into the early 1800s. These two features are confirmed by SSA analysis (not shown) and are shared by NH temperature reconstructions. We compare in Fig. 9 the alkenone SST signal with the sum $\Sigma=($ RC 1$)+($ RCs $6-8)$ of the corresponding components in $\delta^{18} \mathrm{O}$. This partial $\Sigma$ reconstruction of our calcite record reproduces fairly well the SST variations, while we noted above that there is little agreement between the raw $\delta^{18} \mathrm{O}$ data and the alkenone series; see again Fig. 8 and its discussion. Two more remarks regarding Fig. 9 are in order. 
First, the amplitude of the 200-y oscillation in the calcite $\delta^{18} \mathrm{O}$ before $1850 \mathrm{AD}$ is of about $0.06 \%$; according to the Shackleton relationship (Shackleton and Kennet, 1975), this range corresponds to roughly $0.3^{\circ} \mathrm{C}$, while the SST variation on this time scale is of about $1^{\circ} \mathrm{C}$. This argument suggests a contribution by the isotopic composition of water to this bicentennial component in the calcite record. Consider a measured decrease of calcite $\delta^{18} \mathrm{O}$ - similar to that between a maximum and a minimum of the $200-y$ oscillation - that would be accompanied by a synchronous increase of the $\delta^{18} \mathrm{O}$ in the water, due for instance to a decrease in the net difference between precipitation and evaporation; the corresponding temperature change, calculated from the Shackleton equation, would be greater than the one calculated assuming the $\delta^{18} \mathrm{O}$ of water to be constant.

Second, we note in the figure that, from about 1400 to $1800 \mathrm{AD}$, a phase shift occurs between the $\Sigma$ of our calcite record and the alkenone-derived SSTs, with $\delta^{18} \mathrm{O}$ leading SSTs by about 20-30y. This shift could be explained in terms of seasonal effects, by the fact that the alkenones reflect winter-spring, while $\delta^{18} \mathrm{O}$ reflects fall temperatures, respectively. In fact, Luterbacher et al. (2004) reconstructed separate winter and summer temperatures; see Fig. 1a and b of their paper. A comparison of these two figures allows one to identify a shift of the order of $20 \mathrm{y}$ between recognizable features, e.g. between the temperature maxima around the middle of the 1700s and between the maxima in the first half of the 1900s. We are currently examining additional evidence for such phase shifts.

More detailed comparisons between the alkenone record and either our calcite $\delta^{18} \mathrm{O}$ record or the temperature series of Figs. 6 and 7 are hampered by two shortcomings of the alkenone record. First, this time series results from the composition of the measurements performed on three different cores. Though they were extracted form the same Gallipoli Terrace, and dated with the same accuracy, an unexplained difference of about $1^{\circ} \mathrm{C}$ among the separate records is present (Versteegh et al., 2007). Second, the composite series still has several gaps between 1300 and $1500 \mathrm{AD}$; see again Fig. 8. To infer more systematically, from calcite $\delta^{18} \mathrm{O}$ and alkenone measurements, information about past water- $\delta^{18} \mathrm{O}$ variations, it will be necessary to measure a longer, homogeneous series of another proxy for past SSTs, for instance foraminiferal $\mathrm{Mg} / \mathrm{Ca}$ (Chave, 1954).

\section{The Roman Classical Period (RCP)}

The high $\delta^{18} \mathrm{O}$ values measured around the beginning of the Current Era, as described by the trend RC-1 in Fig. 5, require further discussion. Although most $\delta^{18} \mathrm{O}$ variations over the last millennium can be correlated and are in phase with known climate oscillations, such as the Dark Ages (DA), the MO and the LIA, the low temperatures suggested by our record around $0 \mathrm{AD}$ disagree with the relative warmth of-

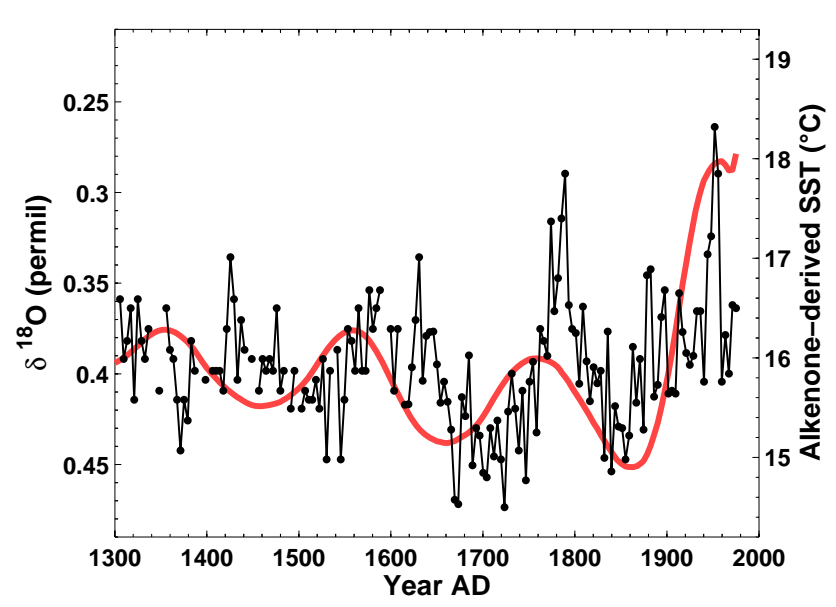

Fig. 9. Alkenone-based SST record of Fig. 6, in black, and sum of $\delta^{18} \mathrm{O}$ RCs 1 (long-term trend) and 6-8 (200-y oscillation), in bold solid red.

ten attributed to the "Roman Classical Period" (RCP). Evidence for and against high temperatures during the RCP is discussed in the following paragraphs.

Temperature profiles in the GRIP and Dye-3 ice cores indicate cold temperatures, though higher than during the LIA (Dahl-Jensen et al., 1998, see Fig. 10 here, first panel). Bond et al. (2001) showed that around 0 AD the temperatures in high northern latitudes were comparable to those during the LIA. DeMenocal et al. (2000; see Fig. 10 here, third panel) reported very low SSTs off western Africa at about 2000 y BP, i.e. around 0 AD. Martínez-Cortizas et al. (1999) analyzed a peat bog record that indicates a local temperature minimum around $2000 \mathrm{BP}$, followed by a long warm period. A study of wood buried in the Roman siege ramp of the Masada fortress near the Dead Sea also suggests a cold and wet period around $70 \mathrm{AD}$ (Issar and Yakir, 1997).

The SST profile at the Bermuda Rise measured by Keigwin (1996; see Fig. 10 here, second panel) shows a temperature decrease between $200 \mathrm{BC}$ and $200 \mathrm{AD}$; its temperature minimum is thus somewhat delayed with respect to the above-mentioned references.

Mangini et al. (2005) translated a well-dated $\delta^{18} \mathrm{O}$ isotopic record of a stalagmite from the Central Alps (Spannagel cave) into a highly resolved temperature record covering the past $2000 \mathrm{y}$. This record shows remarkably low temperatures around $0 \mathrm{AD}$, of about $1.5^{\circ} \mathrm{C}$ lower than during the Medieval Warm Period (MWP). This evidence, in particular, coming from a site that lies relatively close to our area of interest, confirms the evidence from our $\delta^{18} \mathrm{O}$ record of a relatively cold RCP. Mangini et al. (2005) also suggest that this period was dry, which would point to a possible salinity contribution to the $\delta^{18} \mathrm{O}$ variation.

In contrast to these arguments in favor of cool conditions around $0 \mathrm{AD}$, there are other proxy records that point instead to relatively high temperatures. A recent high-resolution 


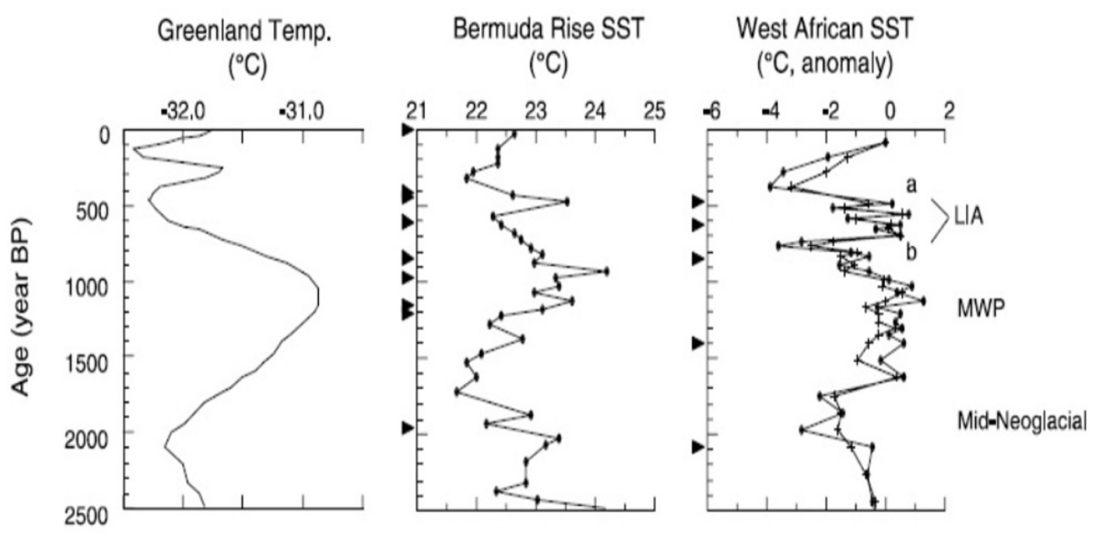

Fig. 10. High-resolution records from Greenland ice cores (first panel, Dahl-Jensen et al., 1998), from the western North Atlantic (Bermuda Rise; second panel, Keigwin, 1996), and from the eastern subtropical North Atlantic (DeMenocal et al., 2000, third panel). From DeMenocal, P., Ortiz, J., Guilderson, T., and Sarnthein, M.: coherent high- and low-latitude climate variability during the Holocene Warm Period, Science, 288, 2198-2202, 2000. Reprinted with permission from AAAS (www.sciencemag.org).

record from the Atlantic, off North Iceland (Sicre et al., 2008), reports SSTs between 0 and 100 AD that are similar to those observed during the MWP.

Several proxies of glacier retreat (Holzhauser et al., 2005; Joerin et al., 2006) and of low lake levels on the Swiss plateau indicate warm and/or dry conditions in the Alps during the RCP. A recent review (Reale and Dirmeyer, 2000) of Mediterranean climate history indicates a gradual drying and warming between the Greek Classical Period (5th century $\mathrm{BC}$ ) and the Late Roman Period (5th century AD). This warming trend continues until $900 \mathrm{AD}$, followed by relatively high temperatures between 900 and $1300 \mathrm{AD}$.

A climate simulation using the general circulation model of Reale and Shukla (2000) suggests possibly dry conditions over the Mediterranean during the RCP, due to changes in atmospheric circulation. Schilman et al. (2001) found a prominent positive peak of about $0.5 \%$ in $\delta^{18} \mathrm{O}$ at this time, in an Eastern Mediterranean marine-sediment record, and interpreted this peak as an indication of increased aridity in the Eastern Mediterranean region.

The preponderence of evidence thus seems to support cold conditions during the RCP in and around the Mediterranean basin. The evidence in support of a decrease of precipitations in this area during the RCP is even more solid. It is this dryness of the climate, rather than its warmth, that could explain the widely accepted reduction of the glacial extent and lake levels in the Alps.

The decrease in Alpine precipitations could also have reduced the freshwater inflow into the Adriatic Sea, especially through the Po River. As a consequence, the salinity and hence the $\delta^{18} \mathrm{O}$ of the Adriatic waters flowing into the Gulf of Taranto might have increased. This isotopic change of the water, as much as the lower temperatures, could have contributed to the high $\delta^{18} \mathrm{O}$ values measured in our core at the beginning of the Current Era.

\section{Conclusions}

A 2200-year-long, high-resolution record of foraminiferal $\delta^{18} \mathrm{O}$ from a sediment core drilled in the Gulf of Taranto (Fig. 1) was measured and studied (Figs. 2 and 3). The time series analysis, carried out by advanced spectral methods, reveals the presence of highly significant oscillatory components with periods of roughly $600,350,200,125$ and $11 \mathrm{y}$ (Figs. 4 and 5).

We compared the $\delta^{18} \mathrm{O}$ components with several proxy records of Northern Hemisphere (NH) temperatures, as well as with European and Italian temperature series and with an alkenone-based SST record measured in the same area (Figs. 6-8). We recall here, once more, that the absolute dating of our Gulf of Taranto cores, based on a reliable sample of historically documented volcanic markers over the last two millennia, ensures an uncommon reliability in the timing of the climate proxies we analyzed.

The alkenone record is in good agreement with the nearby continental temperature series (Fig. 9) and suggests that the sum $\Sigma$ of the trend and 200-y oscillation in our $\delta^{18} \mathrm{O}$ record is temperature-driven. During the last millennium, these two components show a minimum at the Medieval Optimum and a maximum at the Little Ice Age.

In the preceding millennium, the high $\delta^{18} \mathrm{O}$ values arguably suggest low temperatures in a period which coincides in part with the Roman Classical Period (RCP), thus contradicting the commonly alleged warmth of this period (Fig. 10). While broadly accepted effects of drier climate and hence higher salinity may explain at least part of this $\delta^{18} \mathrm{O}$ maximum, additional proxy-record analyses are needed in order to disentangle the temperature and salinity effects. Due to the limitations of the alkenone measurements described in Sect. 4, we are planning to perform measurements on other SST proxies, such as foraminiferal $\mathrm{Mg} / \mathrm{Ca}$ ratios. 


\section{Appendix A}

\section{Stable isotope analysis}

In order to obtain the $\delta^{18} \mathrm{O}$ value of the samples, taken with a spacing of $2.5 \mathrm{~mm}$, we soaked $5 \mathrm{~g}$ of sediment in $5 \%$ calgon solution overnight, then treated it in $10 \% \mathrm{H}_{2} \mathrm{O}_{2}$ to remove any residual organic material, and subsequently washed it with a distilled-water jet through a sieve with a $150 \mu \mathrm{m}$ mesh. The fraction $>150 \mu \mathrm{m}$ was kept and oven-dried at $50^{\circ} \mathrm{C}$. The planktonic foraminifera Globigerinoides ruber were picked out of the samples under the microscope. For each sample, 20-30 specimens were selected from the fraction comprised between $150 \mu \mathrm{m}$ and $300 \mu \mathrm{m}$.

The use of a relatively large number of specimens for each sample removes the isotopic variability of the individual organisms, giving a more representative $\delta^{18} \mathrm{O}$ value. The stable isotope measurements were performed using a VGPRISM mass spectrometer fitted with an automated ISOCARB preparation device. Analytical precision based on internal standards was better than $0.1 \%$. Calibration of the mass spectrometer to VPDB scale was done using NBS19 and NBS18 carbonate standards.

\section{Appendix B}

\section{B1 Singular Spectrum Analysis (SSA)}

The SSA methodology involves three basic steps: (1) embedding a time series of length $N$ in a vector space of dimension $M$ (for the choice of $M$, see Vautard et al. (1992); Ghil et al. (2002)); (2) computing the $M \times M$ lag-covariance matrix $\mathbf{C}_{\mathbf{D}}$ of the data (see the two different approaches of Broomhead et al., 1986 and Vautard and Ghil, 1989); and (3) diagonalizing $\mathrm{C}_{\mathbf{D}}$ :

$\Lambda_{\mathrm{D}}=E_{D}^{T} \mathrm{C}_{\mathrm{D}} E_{D}$

where $\boldsymbol{\Lambda}_{\mathbf{D}}=\operatorname{diag}\left(\lambda_{1}, \lambda_{2}, \ldots \lambda_{M}\right)$, with $\lambda_{1}, \lambda_{2}, \ldots \lambda_{M} \geq 0$, and $\mathbf{E}_{\mathbf{D}}$ is the $M \times M$ matrix having the corresponding eigenvectors $\boldsymbol{E}_{\boldsymbol{k}}, k=1, \ldots, M$ as its columns. For each $\boldsymbol{E}_{\boldsymbol{k}}$ we construct the time series, of length $N-M+1$, called the $k$-th principal component (PC); this $\mathrm{PC}$ represents the projection of the original time series on the eigenvector $\boldsymbol{E}_{\boldsymbol{k}}$ (also called empirical orthogonal function, EOF). Each eigenvalue $\lambda_{k}$ gives the variance of the corresponding PC; its square root is called singular value $(\mathrm{SV})$. Given a subset $\mathcal{K}=\left(k_{1}^{*}, k_{2}^{*}, \ldots, k_{K}^{*}\right)$ of eigenvalues, it is possible to extract time series of length $N$, by combining the corresponding PCs; these time series are called reconstructed components (RCs) and capture the variability associated with the $K$ eigenvalues of interest.

\section{B2 Monte Carlo SSA (MC-SSA)}

In order to reliably identify the trend and oscillations of the $\delta^{18} \mathrm{O}$ time series, we used the Monte Carlo method (MCSSA) (Allen and Smith, 1996). In this approach, we assume a model for the analysed time series (null-hypothesis) and we determine the parameters using a maximum-likelihood criterion. Then a Monte Carlo ensemble of surrogate time series (size 10000) is generated from the model and SSA is applied to data and surrogates (EOFs of the null-hypothesis basis are used), in order to test whether it is possible to distinguish the series from the ensemble. Since a large class of geophysical processes generate series with larger power at lower frequencies, we have assumed AR(1) noise in evaluating evidence for trend and oscillations. This is done to avoid overestimating the system's predictability, by underestimating the amplitude of the stochastic component of the time series (Allen and Smith, 1996).

Acknowledgements. It is a pleasure to honor by this paper the lifelong contributions of André Berger, a close friend of one of the authors (M. G.): having contributed substantially to the understandings of the link between secular changes in the planetary orbits and glaciation cycles on Earth, André Berger turned his attention to the recent past and the future of Earth's climate.

We also wish to recall the memory of Giuliana Cini Castagnoli, who lead the Cosmogeophysics Group at Torino for many years, and of Giuseppe Bonino, who contributed significantly to this study. We are grateful to the late Carlo Castagnoli for stimulating discussions and support.

We wish to thank S. M. Bernasconi (Geological Institute, ETH, Zürich, Switzerland) for the mass spectrometer measurements of $\delta^{18} \mathrm{O}$, for drawing our attention to several papers on climate proxy records, and for several interesting discussions; J. C. Duplessy for his constructive comments; M. Maugeri and J. Luterbacher for making the Italian and European temperature records available, respectively; J. W. de Leeuw and G. J. M. Versteegh for the alkenones measurements performed in collaboration with the Torino group; A. Romero for his dedicated technical assistance.

This collaborative research was supported by the European Commission's Project No. 12975 (NEST) "Extreme events: Causes and consequences (E2-C2)". MG's work was also partially supported by US Department of Energy grant DE-FG02-07ER64439 from its Climate Change Prediction Program.

Edited by: M. Crucifix

\section{References}

Allen, M. R. and Smith, L. A.: Monte Carlo SSA: detecting oscillations in the presence of coloured noise, J. Climate, 9, 3373-3404, 1996.

Arnò, V., Principe, C., Rosi, M., Santacroce, R., Sbrana, A., and Sheridan, M. F.: Eruptive History, in: Summa-Vesuvius, Quaderni de La Ricerca Scientifica, edited by: Santacroce R., CNR, Roma, Italy, 114(8), 53-103, 1987. 
Boiseau, M., Ghil, M., and Juillet-Leclerc, A.: Climatic trends and interdecadal variability from South-Central Pacific coral records, Geophys. Res. Lett., 26, 2881-2884, 1999.

Bond, G., Kromer, B., Beer, J., Muscheler, R., Evans, M. N., Showers, W., Hoffmann, S., Lotti-Bond, R., Hajdas, I., and Bonani, G.: Persistent solar influence on North Atlantic climate during the Holocene, Science, 294(5549), 2130-2136, 2001.

Bonino, G., Cini Castagnoli, G., Callegari, E., and Zhu, G. M.: Radiometric and tephroanalysis dating of recent Ionian sea cores, Nuovo Cimento C, 16, 155-161, 1993.

Brohan, P., Kennedy, J. J., Harris, I., Tett, P., and Jones, P. D.: Uncertainty estimates in regional and global observed temperature changes: a new dataset from 1850, J. Geophys. Res., 111, D12106, doi:10.1029/2005JD006548, 2006.

Broomhead, D. S. and King, G. P.: Extracting qualitative dynamics from experimental data, Physica D, 20, 217-236, 1986.

Brunetti, M., Maugeri, M., Monti, F., and Nanni, T.: Temperature and precipitation variability in Italy in the last two centuries from homogenised instrumental time series, Int. J. Climatol., 26, 345381, 2006

Bryan, F.: High-latitude salinity effects and interhemispheric thermohaline circulations, Nature, 323, 301-304, 1986.

Chave, K. E.: Aspects of the biogeochemistry of Magnesium. 1. Calcareous marine organisms, J. Geol., 62, 266-599, 1954.

Cini Castagnoli, G., Bonino, G., Caprioglio, F., Provenzale, A., Serio, M., and Zhu, G. M.: The carbonate profile of two recent Ionian sea cores: evidence that the sedimentation rate is constant over the last millenia, Geophys. Res. Lett., 17, 1937-1940, 1990.

Cini Castagnoli, G., Bonino, G., Provenzale, A., Serio, M., and Callegari, E.: The $\mathrm{CaCO}_{3}$ profiles of deep and shallow Mediterranean sea cores as indicators of past solar-terrestrial relationship, Nuovo Cimento C, 15, 547-563, 1992a.

Cini Castagnoli, G., Bonino, G., Serio, M., and Sonett, C. P.: Common spectral features in the 5500-year record of total carbonate in sea sediments and radiocarbon in tree rings, Radiocarbon, 34(3), 798-805, 1992b.

Cini Castagnoli, G., Bonino, G., Della Monica, P., and Taricco, C.: Record of thermoluminescence in sea sediments in the last millennia, Nuovo Cimento C, 20(1), 1-8, 1997.

Cini Castagnoli, G., Bonino, G., and Taricco, C.: The global and persistent millennial-scale variability in the thermoluminescence profiles of shallow and deep Mediterranean sea cores, Nuovo Cimento C, 21, 453-460, 1998.

Cini Castagnoli, G., Bonino, G., Della Monica, P., Taricco, C., and Bernasconi, S. M.: Solar activity in the last millennium recorded in the $\delta^{18} \mathrm{O}$ profile of planktonic foraminifera of a shallow water Ionian Sea core, Solar Physics, 188(1), 191-202, 1999.

Cini Castagnoli, G., Bonino, G., and Taricco, C.: Long term solarterrestrial records from sediments: carbon isotopes in planktonic foraminifera during the last millennium, Adv. Space Res., 29(10), 1537-1549, 2002a.

Cini Castagnoli, G., Bonino, G., Taricco, C., and Bernasconi S. M.: Solar radiation variability in the last 1400 years recorded in the carbon isotope ratio of a mediterranean sea core, Adv. Space Res., 29(12), 1987-1994, 2002b.

Cini Castagnoli, G., Taricco, C., and Alessio, S.: Isotopic record in a marine shallow-water core: imprint of solar centennial cycles in the past 2 millennia, Adv. Space Res., 35, 504-508, 2005.

Crowley, T. J.: Causes of climate change over the past 1000 years,
Science, 289(5477), 270-277, 2000.

Dahl-Jensen, D., Mosegaard, K., Gundestrup, N., Clow, G. D., Johnsen, S. J., Hansen, A. W., and Balling, N.: Past temperatures directly from the Greenland ice sheet, Science, 282, 268-271, 1998.

DeMenocal, P., Ortiz, J., Guilderson, T., and Sarnthein, M.: Coherent high- and low-latitude climate variability during the Holocene Warm Period, Science, 288, 2198-2202, 2000.

Dettinger, M. D., Ghil, M., and Keppenne, C. L.: Interannual and interdecadal variability in United States surface-air temperatures, 1910-87, Climatic Change, 31, 35-66, 1995.

Esper, J., Cook, E. R., ans Schweingruber, F. H.: Low-frequency signals in long tree-ring chronologies and the reconstruction of past temperature variability, Science, 295(5563), 2250-2253, 2002.

Esper, J., Frank, D. C., and Wilson, R. J. S.: Climate reconstructions - low frequency ambition and high frequency ratification, Eos Trans. AGU, 85(12), 113-120, 2004.

Folland, C. K. and Karl, T.L.: Recent rates of warming in marine environment meet controversy, Eos Trans. AGU, 82(40), 453459, 2001.

Ghil, M.: Hilbert problems for the geosciences in the 21st century, Nonlin. Processes Geophys., 8, 211-211, 2001, http://www.nonlin-processes-geophys.net/8/211/2001/.

Ghil, M. and Taricco, C.: Advanced spectral analysis methods, in: Past and Present Variability of the Solar-terrestrial System: Measurement, Data Analysis and Theoretical Models, edited by: Cini Castagnoli, G. and Provenzale, A., IOS Press, Amsterdam, The Netherlands, 137-159, 1997.

Ghil, M. and Vautard, R.: Interdecadal oscillations and the warming trend in global temperature time series, Nature, 350, 324-327, 1991.

Ghil, M., Allen, M. R., Dettinger, M. D., Ide, K., Kondrashov, D., Mann, M. E., Robertson, A. W., Saunders, A., Tian, Y., Varadi, and F., Yiou, P.: Advanced spectral methods for climatic time series, Rev. Geophys., 40(1), 3.1-3.41, 2002.

Guo, W., Wang, Y., and Brown, M. B.: A signal extraction approach to modelling hormone time series with pulses and a changing baseline, J. Am. Stat. Assoc., 94(447), 746-756, 1999.

Holzhauser, H., Magny, M., and Zumbühl, H. J.: Glacier and lakelevel variations in west-central Europe over the last 3500 years, The Holocene, 15(6), 789-801, 2005.

Issar, A. S. and Yakir D.: Isotopes from wood buried in the Roman siege ramp of Masada: The Roman Period's colder climate, The Biblical Archaeologist, 60(2), 101-106, 1997.

Joerin, U. E., Stocker, T. F., and Schlüchter, C. : Multicentury glacier fluctuations in the Swiss Alps during the Holocene, The Holocene, 16(5), 697-704, 2006.

Jones, P. D.: Climate Variations and Forcing Mechanisms of the Last 2000 Years, edited by: Bradley, S. and Jouzel, J., NATOASI Series I, Springer-Verlag, Berlin, Germany, 649 pp., 1996.

Jones, P. D., Briffa, K. R., Barnett, T. P., and Tett, S. F. B.: Highresolution palaeoclimatic records for the last millenium, The Holocene, 8(4), 455-471, 1998.

Jones, P. D., New, M., Parker, D. E., Martin, S., and Rigor, I. G.: Surface air temperature and its changes over the past 150 years, Rev. Geophys., 37, 173-199, 1999.

Keigwin, L. D.: The Little Ice Age and Medieval Warm Period in the Sargasso Sea, Science, 274(5292), 1504-1508, 1996. 
Krishnaswamy, S., Lal, D., Martin, J. M., and Meybeck, M.: Geochronology of lake sediments, Earth Planet. Sci. Lett., 11, 407-414, 1971.

Labitzke, K. and Matthes, K.: Eleven-year solar cycle variations in the atmosphere: observations,mechanisms and models, The Holocene, 13(3), 311-317, doi:10.1191/0959683603hl623rp, 2003.

Lean, J., Beer, J., and Bradley, R.: Reconstruction of Solar Irradiance since 1610: Implications for Climate Change, Geophys. Res. Lett., 22(23), 3195-3198, 1995.

Luckman, B. H., Briffa, K. R., Jones, P. D., and Schweingruber, F. H.: Tree-ring based reconstruction of summer temperatures at the Columbia Icefield, Alberta, Canada, AD 1073-1983, The Holocene, 7(4), 375-389, 1997.

Luterbacher, J., Dietrich, D., Xoplaki, E., Grosjean, M., and Wanner, H.: European seasonal and annual temperature variability, trends and extremes since 1500, Science, 303,1499-1503, 2004.

Mangini, A., Spötl, C., and Verdes, P.: Reconstruction of temperature in the Central Alps during the past $2000 \mathrm{yr}$ from a $\delta^{18} \mathrm{O}$ stalagmite record, Earth Planet. Sci. Lett., 235, 741-751, 2005.

Mann, M. E., Bradley, R. S., and Hughes, M. H.: Northern Hemisphere temperatures during the past millennium: inferences, uncertainties, and limitations, Geophys. Res. Lett., 26(6), 759-762, 1999.

Marcus, S. L., Ghil, M., and Ide, K.: Models of solar irradiance variability and the instrumental temperature record, Geophys. Res. Lett., 26, 1449-1452, 1999.

Martínez-Cortizas, A., Pontevedra-Pombal, X., García-Rodeja, E., Nóvoa-Muñoz, J. C., and Shotyk, W.: Mercury in a Spanish peat bog: archive of climate change and atmospheric metal deposition, Science, 284, 939-942, 1999.

Martinson, D. G., Bryan, K., Ghil, M., Hall, M. M., Karl, T. R., Sarachik, E. S., Sorooshian, S., and Talley, L. D. (Eds): Natural Climate Variability on Decade-to-Century Time Scales, in: National Research Council of the National Academies, National Academy Press, Washington DC, USA, 630 pp., 1995.

Metaxas, D. A., Bartzokas, A., and Vitsas, A.: Temperature fluctuations in the Mediterranean area during the last 120 years, Int. J. Climatol., 11, 897-908, 1991.

Naveau, P., Ammann, C., Oh, H. S., and Guo, W.: An automatic statistical methodology to extract pulse like forcing factors in climatic time series: Application to volcanic events, edited by: Robock, A., Volcanism and the Earth's Atmosphere, Geophysical Monograph, 139, 177-186, 2003.

National Research Council: Surface Temperature Reconstructions for the Last 2000 Years, National Academy Press, Washington DC, USA, 145 pp., 2006.

Parker, D. E.: Effects of changing exposure of thermometers at land stations, Int. J. Climatol., 14, 1-31, 1994.

Pierre, C.: The oxygen and carbon isotope distribution in the Mediterranean water masses, Mar. Geol., 153, 41-55, 1999.

Plaut, G., Ghil, M., and Vautard, R.: Interannual and interdecadal variability in 335 years of Central England temperatures, Science, 268, 710-713, 1995.

Rabiner, L. R., McClellan, J. H., and Parks, T. W.: FIR Digital Filter Design Techniques Using Weighted Chebyshev Approximations, Proc. IEEE, 63, 595-610, 1975.
Reale, O. and Dirmeyer, P.: Modeling the effects of vegetation on Mediterranean climate during the Roman classical period. Part I: History and model sensitivity, Global Planet. Change, 25, 163184, 2000.

Reale, O. and Shukla, J: Modeling the effects of vegetation on Mediterranean climate during the Roman Classical Period: Part II. Model simulation, Global Planet. Change, 25, 185-214, 2000.

Schilman, B., Bar-Matthews, M., Almogi-Labin, A., and Luz, B.: Global climate instability reflected by Eastern Mediterranean marine records during the late Holocene, Palaeogeogr. Palaeocl., 176, 157-176, 2001.

Shackleton, N. J. and Kennett, J. P.: Palaeo-temperature history of the Cenozoic and the initiation of Antarctic glaciation: Oxygen and carbon isotope analysis in DSDP sites 277, 279 and 281, in: Initial Reports of the Deep Sea Drilling Project, edited by: Kennett, J. P. and Houtz, R. E., US Government Printing Office, Washington DC, USA, 5, 743-755, 1975.

Sicre, M. A., Jacob, J., Ezat, U., Rousse, S., Kissel, C., Yiou, P., Eiriksson, J., Knudsen, K. L., Jansen, E., and Turon, J. L.: Decadal variability of sea surface temperatures off North Iceland over the last 2000 yrs, Earth Planet. Sci. Lett., 268, 137-142, doi:10.1016/j.epsl.2008.1001.1011, 2008.

Stommel, H.: Thermohaline convection with two stable regimes of flow, Tellus, 13, 224-230, 1961.

Stuiver, M. and Braziunas, T. F.: Sun, ocean, climate and atmospheric ${ }^{14} \mathrm{CO}_{2}$ : an evaluation of causal and spectral relationship, The Holocene, 3(4), 289-305, 1993.

Taricco, C., Alessio, S., and Vivaldo, G.: Sequence of eruptive events in the Vesuvio area recorded in shallow-water Ionian Sea sediments, Nonlin. Processes Geophys., 15, 25-32, 2008, http://www.nonlin-processes-geophys.net/15/25/2008/.

Torrence, C. and Compo, G. P.: A practical guide to wavelet analysis, B. Am. Meteorol. Soc., 79, 61-78, 1998.

Tzipermann, E.: Inherently unstable climate behaviour due to weak thermohaline ocean circulation, Nature, 386, 592-595, 1997.

Von Storch, H., Zorita, E., Jones, J. M., Dimitriev, Y., GonzálezRouco, F., and Tett, S. F. B.: Reconstructing past climate from noisy data, Science, 306, 679-682, 2004.

Vautard, R., Yiou, P., and Ghil, M.: Singular-spectrum analysis: A toolkit for short, noisy chaotic signals, Physica D, 58, 95-126, 1992.

Vautard, R. and Ghil, M.: Singular Spectrum Analysis in Nonlinear Dynamics, with Applications to Paleoclimatic Time Series, Physica D, 35, 395-424, 1989.

Versteegh, G. J. M., de Leeuw, J. W., Taricco, C., and Romero, A.:Temperature and productivity influences on Uk37 and their possible relation to solar forcing of the Mediterranean winter, Geochem. Geophys. Geosy., 8, Q09005, doi:10.1029/2006GC001543, 2007.

Vivaldo, G., Taricco, C., Alessio, S., and Ghil, M: Accurate dating of Gallipoli Terrace (Ionian Sea) sediments: Historical eruptions and climate records, PAGES News, 17(1), 8-9, 2009.

White, W. B., Lean, J., Cayan, D. R., and Dettinger, M. D.: A response of global upper ocean temperature to changing solar irradiance, J. Geophys. Res., 102, 3255-3266, 1997. 